\title{
Investigating the Relationship between Learning Style Preferences and Teaching Collaboration Skills and Technology: An Exploratory Study ${ }^{1}$
}

Seung-Lye Kim

University of North Carolina at Chapel Hill, CB \#3360, Chapel Hill, NC 27599

kims@ils.unc.edu

Diane H. Sonnenwald

University of North Carolina at Chapel Hill, CB \#3360, Chapel Hill, NC 27599

sonnenwald@ils.unc.edu

Published in 2002. In E. Toms, Proceedings of the ASIS\&T Conference (pp.64-73). NJ: Information Today.

This paper reports on an exploratory study that investigates the relationship between participants' learning style preferences and their perceptions of a professional workshop on collaboration and technology to support collaboration. The Learning Preference ScaleStudents (LPSS) (Owens \& Barnes, 1992) was administered to identify participants' learning style preferences as cooperative, competitive and/or individualized. Using cluster analysis two groups, or categories, of learning style preferences among the participants emerged. Group 1 showed a strong preference for the cooperative learning style, and Group 2 showed a strong preference for competitive and cooperative learning styles. Group 1 rated the workshop more positively than Group 2. However, Group 2 reported a larger increase in self-efficacy compared to those in Group 1 $(18.9 \%$ vs. $6.0 \%)$. Both groups provided different suggestions regarding the content of the workshop. Group 1 suggested adding more discussions and group exercises, whereas Group 2 suggested adding explicit theory or rules to govern behavior. These findings indicate that learning styles should be considered as a potential variable that influences learning outcomes and preferences.

${ }^{1}$ This paper is based upon work supported by the STC Program of National Science Foundation under Agreement No. CHE-9876674

\section{INTRODUCTION}

The interest in implementing collaborative practices is continually growing in research and development (R\&D), industrial and non-profit organizations. No single individual, profession or organization can possibly possess all the required knowledge and skills to solve complex problems. Therefore, interdisciplinary, interorganizational and geographically distributed collaboration is increasingly important to integrate knowledge, skills and abilities (Simonin, 1997; Stevens \& Campion, 1994).

For example, many information and library science professionals must now work in "distributed teams" or "virtual teams" using information and communications technology (ICT) in an effort to overcome the constraints of distance, time zones and organizational boundaries. However, different patterns of work activities, expectations, organizational constraints, and personal beliefs and knowledge make it difficult for individuals to collaborate, explore, and share one another's specialized knowledge. These differences are often what bring collaborators together, but at the same time causes them to challenge or contest one another's contributions and roles during the collaboration (Sonnenwald, 1995; Sonnenwald \& Pierce, 2000).

To overcome these problems, there has been a trend toward training or teaching collaboration skills in recent years (Cannon-Bowers, Tannenbaum, Salas \& Volpe, 1995; Cooley, 1994; Simonin, 1997). Research shows educational programs that provide a group with assistance regarding aspects of collaborative work, for which members do not presently have adequate knowledge, skill, or experience, are an essential aspect of effective collaboration (Hackman \& Walton, 1986; Lurey, 1998). However, we do not know if individuals' learning styles impact the 
effectiveness of such professional training programs.

This paper discusses an exploratory study investigating learning styles and their impact on learning and adopting collaboration skills and information and communications technology to support collaboration. To assess learning styles, we used the cooperative, competitive and individualized learning style theory and related instruments (Johnson \& Johnson, 1978, Owens \& Barnes, 1992). To select educational effectiveness measures, research on training fulfillment (Tannenbaum, Mathieu, Salas \& Cannon-Bowers, 1991), learning outcomes (Kraiger, Ford \& Salas, 1993), self-efficacy (Bandura, 1976), and cooperative learning (Johnson \& Johnson, 1984; Mainzer, Slavin \& Lowry, 1993) was synthesized. Four types of educational effectiveness measures were identified: measures of perceived selfefficacy, organizational commitment, motivation and overall perceptions of the educational experience. Previous research suggests the degree of self-efficacy, commitment, and motivation prior to training is directly related to those after training (Gist, 1986; Baldwin \& Ford, 1988; Tannenbaum et al., 1991). Therefore we collected data regarding participants' self-efficacy, motivation and organizational commitment before and after the workshop. We collected data regarding participants' overall perceptions of the workshop immediately after each workshop session. This approach is learner-oriented, that is, the analysis is based on students' perspectives.

Study participants were chemistry and chemical engineering undergraduate, graduate students and postdoctoral fellows who were members of a geographically distributed research and development center. They attended a two-day workshop on collaboration and ICT to support collaboration.

Although this was a pilot study with a limited number of participants, results indicate participants with a strong preference for the cooperative and competitive learning styles reported a larger increase in self-efficacy compared to those with a strong preference primarily for the cooperative learning style (18.9\% vs. $6.0 \%)$. All participants provided different suggestions regarding the content of the workshop. Participants with a strong preference primarily for the cooperative learning style suggested adding more discussions and group exercises. In comparison, participants with a strong preference for the cooperative and competitive learning styles suggested adding explicit theory or rules to govern behavior. These findings indicate that learning styles should be considered as a potential variable that influences learning outcomes, and that different learning style preferences should be considered when designing and implementing professional workshops.

\section{LEARNING STYLES}

Learning styles are individual preferences and tendencies that influence learning (Smith, 1982). There can be a strong relationship between learning styles and attitudes towards learning, including motivation to learn, involvement in learning activities, attitudes towards instructors, and selfefficacy (Johnson \& Johnson, 1978). Therefore, learning styles may be an important variable that influences the effectiveness of any professional training or educational program.

There are many different learning preferences described in the literature. In this study, we investigated cooperative, competitive and individualized learning styles (Owens \& Straton, 1980, Owens \& Barnes, 1992). The cooperative learning style indicates a preference for achieving individual goals while working conjointly with peers. The competitive learning style indicates a preference for learning in competition with others, often achieving individual goals when others fail to achieve their goals. An individualized learning style indicates a preference for achieving individual goals having no involvement with peers (Owens \& Straton, 1980).

Owens and Barnes (1992) developed a survey instrument, the Learning Preference Scale-Students (LPSS), to help researchers investigate these learning styles. The instrument has been widely tested and shown to be valid and reliable (e.g., Johnson \& Engelhard, 1992; Johnson, 1993). It consists of 30 questions, with 10 questions for each learning style. For each question, a seven-point semantic differential scale is used with anchors from "strongly disagree" to "strongly agree". Individuals are given a score for each style and the relationships among the three scores determine the learning style preferences for each individual or group of individuals. 


\section{EDUCATIONAL EFFECTIVENESS MEASURES}

3.1 Self-efficacy in collaboration and the use of information and communications technology

Perceived self-efficacy is defined as

individuals' judgments of their capabilities to organize and execute courses of action required to attain a designated type of performance. Selfefficacy is a critical factor because it is based on the individual's belief in one's ability to perform a specific task (Bandura, 1977). Research shows a high correlation between self-efficacy judgments and subsequent performance (Bandura, 1977; Bandura \& Beyer, 1977; Schunk, 1981). Preworkshop self-efficacy has been shown to be positively related to learning during a workshop (Gist, 1986; Gist, Schwoerer \& Rosen, 1989). Moreover, self-efficacy has been shown to relate to task performance in a variety of settings (Barling \& Beattie, 1983; Taylor, Locke, Lee \& Gist, 1984). Self-efficacy is also related to individuals' willingness to try new technology (Hill, Smith \& Mann, 1987). It also has been noted that although learners, or trainees, can obtain relevant knowledge or skills, they may be unable to apply those newly gained knowledge effectively due to their persisting weak self-efficacy perceptions (Gist, 1986). Thus, self-efficacy is considered as both a precursor and an important outcome of training (Tannenbaum, et al., 1991).

To measure perceived self-efficacy in collaboration and the use of ICT, we used survey questions based on research by Heinssen, Glass and Knight (1987) and Henry and Stone (1997). Using self-efficacy theory, Heinssen and colleagues developed the Computer Anxiety Rating Scale (CARS). Henry and Stone develop a computer selfefficacy and outcome expectancy scale. Both scales have been shown to have a high degree of reliability (Heinssen et al., 1987; Henry \& Stone, 1997; Rosen $\&$ Weil, 1994). These scales were chosen as a measure of anxiety of using ICT, which is one's physiological state that represents a source of selfefficacy information. The combined scales have fifteen items, which were used with a 7-point semantic differential scale.

\subsection{Organizational Commitment}

Organizational commitment is the relative strength of an individual's identification with and involvement in a particular organization (Mowday, Porter \& Steers, 1982). It is primarily characterized by three factors: a strong belief in and acceptance of the organization's goals and values; a willingness to exert considerable effort on behalf of the organization; and a strong desire to maintain membership in the organization. An individual's level of organizational commitment has been shown to influence their view of training, for both themselves and the organization (Tannenbaum, et al., 1991). In this study, enhanced organizational commitment is a desired outcome of the workshop.

The Organizational Commitment Questionnaire (OCQ) used in this study was constructed to obtain an overall summary of individual's commitment to an organization (Mowday, Steers \& Porter, 1982). The reliability of this questionnaire has been illustrated in previous research (e.g., Tannenbaum et al., 1991).

\subsection{Motivation to collaborate}

Research has shown that individuals with higher levels of motivation learn more, performs better and are more likely to complete training than their less motivated peers (Baldwin, Magjuka \& Loher, 1991; Mathieu, Tannenbaum \& Salas, 1992). Thus, training/workshop motivation should also be viewed as an important antecedent of training effectiveness. In addition, post-workshop motivation can also be considered as an important outcome of the training process (Noe, 1986; Noe \& Schmitt, 1986).

The scale measuring motivation used in this study is based on expectancy theory developed by Lawler (1981). Expectancy theory proposes that individuals choose among a set of behavioral alternatives on the basis of the motivational force of each alternative (Leonard, Beauvais \& Scholl, 1995). It suggests that the value of rewards, as well as individuals' expectations, ability and perceptions about their role will influence effective effort and therefore their overall performance. Participants' perceptions of the relationship between doing well in the workshop and future work performance were assessed with 6 questions (Lawler, 1981).

\subsection{Participants' Overall Perceptions}

In order to collect additional information about personal responses to the workshop, post-workshop surveys were conducted. The post-workshop survey is based on research by Klatt (1999). This survey 
investigated participants' overall perspectives concerning the workshop; whether they liked it or not, and whether the workshop met their needs and expectations. The survey is a mix of quantitative and open-ended questions.

\section{METHODOLOGY}

\subsection{Setting}

The study took place in an interdisciplinary, multi-institutional, geographically distributed research and development (R\&D) center. The center supports approximately 100 students and scientists conducting research in chemistry and chemical engineering at four universities in the USA. The center strongly encourages members to collaborate as necessary when working to solve complex R\&D problems. Furthermore, the center supports workshops and seminars to help members better understand social processes that foster collaboration and innovation in scientific research and engineering.

In a venue of providing such opportunities to the members, a workshop program on collaboration and ICT was developed by the authors. The workshop is intended to teach practical skills and strategies for collaboration and using ICT to support collaboration across distances. A pilot workshop was designed and conducted before launching the full workshop program. The goals of the pilot were to explore learning styles and effectiveness measures and to enhance the workshop based on the participants' feedback. Members of the $R \& D$ center were invited to participate in the pilot study. The six study participants (all volunteers) were undergraduate students, graduate students and postdoctoral fellows supported by the center. This paper reports on data from the pilot workshop.

\subsection{Collaboration Workshop Program}

The contents of the pilot workshop were based on a thorough review of relevant research in collaboration and information and communication technologies, an analysis of stakeholders' needs assessment and the professional experience of one of the authors. The pilot workshop consisted of two sessions, 7 and 6 hours long, on consecutive days.

The objectives of the first day's workshop were to understand and gain the knowledge and skills on collaboration and current and emerging information and communications technology that support collaboration. During the first day, participants were first given 10 minutes to introduce themselves and to share personal information, including interests and recent activities as well as their primary expectations for the workshop. This activity was intended to provide opportunities for ice breaking among the participants because some had not met each other previously. Following this activity, the participants were introduced to a variety of topics, including the nature of collaboration, benefits of and barriers to collaboration, and strategies and techniques for collaboration. The instructor encouraged the participants to discuss each topic based on their experiences and perceptions. The second part of the first day's program focused on ICT, including current and emerging technologies that support collaboration. Examples of emerging technologies included two collaborative systems, nanoManipulator (Sonnenwald, Maglaughin, Bergquist, Kupstas-Soo \& Whitton, 2001) and 3-D video conferencing systems (Raskar, Welch, Cutts, Lake, Stesin \& Fuchs, 1998) that were demonstrated by researchers in the information and computer science departments at the University of North Carolina at Chapel Hill.

On the second day of the workshop, the participants completed a small group collaboration exercise. The purpose of the exercise was to give participants practical experience in interdisciplinary collaboration. The small group task was to collaboratively design a residence for an alien world. After 1.5 hours, the task ended. Using their experiences during this exercise, the instructor helped participants explore, in an open discussion format, collaboration skills and strategies, including techniques that can be used to prevent and manage conflict. Participants openly expressed differing opinions and experiences, and constructively discussed these differences. Through this experiential activity and discussion, participants also had an opportunity to learn more about collaboration and each other.

\subsection{Data Collection}

As discussed previously, workshop participants were asked to complete the learning style preference questionnaire prior to the workshop. They also completed the surveys designed to measure their attitudes regarding self-efficacy, 
organizational commitment and motivation prior to the workshop and again within a week after the workshop. Furthermore, immediately after each workshop session, participants completed the survey asking for their overall perceptions.

\section{4 Limitations}

The current approach does not investigate behavior changes and knowledge transfer because measuring these types of outcomes is problematic. Measuring behavior change or knowledge transfer may be simple with routine production work, but it is complex and difficult with knowledge work performed by professionals. For example, it takes an extended period of time to begin collaborative projects. Furthermore, many uncontrollable and complex variables such as structures, systems and processes, may influence the collaborative process and outcomes (Sonnenwald, 1999).

This study is exploratory in nature; it is a pilot study with six participants. Further research that includes additional study participants is underway. This subsequent research is necessary to increase the validity of the results.

\section{RESULTS AND DISCUSSION}

\subsection{Learning Style Preferences}

All participants demonstrated a preference for cooperative learning (see Figure 1). The data analysis further revealed that some participants' learning preferences are not clearly distinguishable. For example, participant number 5 shows an almost equal preference for every learning style.

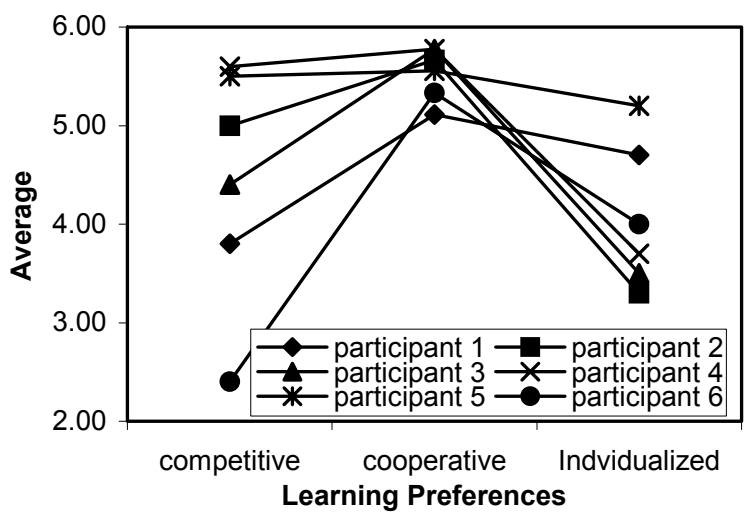

Figure 1. Learning Style Preference Data
Cluster analysis was conducted in order to classify the participants' learning style preferences. We used all combinations of linkages and distance methods in the cluster analysis. The Ward linkage, the most widely used for cluster analysis, and Euclidian distance were applied to produce the final classification of learning preferences (Aldenderfer \& Blashfield, 1984).

Two groups of learning preferences emerged (see Figure 2). Participants (\#1, 2, 3, 5, 6) in Group 1 show a strong preference for cooperative learning, and also some preference for competitive and individualized learning. Participant (\#4) in Group 2 show a strong preference for cooperative and competitive learning but very little preference for individualized learning.

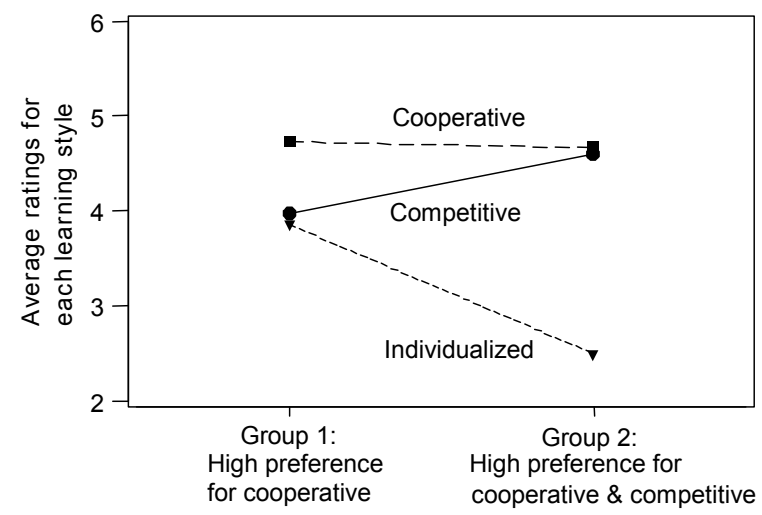

Figure 2. Cluster Analysis of Learning Style Preferences

\subsection{Self-Efficacy, Organizational Commitment and Motivation}

Participants' attitudes towards self-efficacy, organizational commitment and motivation before and after the workshop were summarized (see Table 1). Overall, participants reported positive changes in self-efficacy and commitment, and a slight decrease in motivation.

\subsubsection{Self-efficacy}

Self-efficacy for collaboration and information and communications technology between prior to (mean $=5.68, \mathrm{n}=6)$ and after the workshop (mean= $6.13, \mathrm{n}=4)$ shows a positive increase $(7.9 \%)$. The increases were consistent for both Group 1 and Group 2 learning preferences (see Table 2 \& Figure $3)$. 
Table 1. Pre- \& Post-Workshop Attitudes (survey scale 1-7)

\begin{tabular}{|c|c|c|c|c|c|}
\hline \multirow{2}{*}{ Attitude } & \multicolumn{2}{|c|}{ Pre-workshop $(n=6)$} & \multicolumn{2}{|c|}{ Post-workshop $(\mathrm{n}=4)$} & \multirow{2}{*}{$\%$ change } \\
\hline & Mean & SD & Mean & SD & \\
\hline Self-efficacy & 5.68 & 0.33 & 6.13 & 0.28 & +7.9 \\
\hline Organizational Commitment & 5.33 & 1.18 & 5.45 & 1.03 & +2.3 \\
\hline Motivation & 5.71 & 0.35 & 5.68 & 0.29 & -0.5 \\
\hline
\end{tabular}

Table 2. Pre- \& Post-Workshop Attitudes by Learning Styles (survey scale 1-7)

\begin{tabular}{|c|c|c|c|c|c|c|}
\hline \multirow{2}{*}{ Attitude } & \multicolumn{3}{|c|}{ Group $1^{\mathrm{a}}$} & \multicolumn{3}{|c|}{ Group $2^{\mathrm{b}}$} \\
\hline & Pre $(n=5)$ & Post $(n=$ & change & $\operatorname{Pre}(n=1)$ & Post $(n=$ & o change \\
\hline Self-efficacy & 5.76 & 6.08 & +6.0 & 5.29 & 6.29 & +18.9 \\
\hline Organizational Commitment & 5.04 & 5.07 & +0.6 & 6.80 & 6.60 & -2.9 \\
\hline Motivation & 5.69 & 5.67 & -0.35 & 5.86 & 5.71 & -2.6 \\
\hline
\end{tabular}

${ }^{a}$ High preference for cooperative learning

${ }^{\mathrm{b}}$ High preference for cooperative and competitive learning
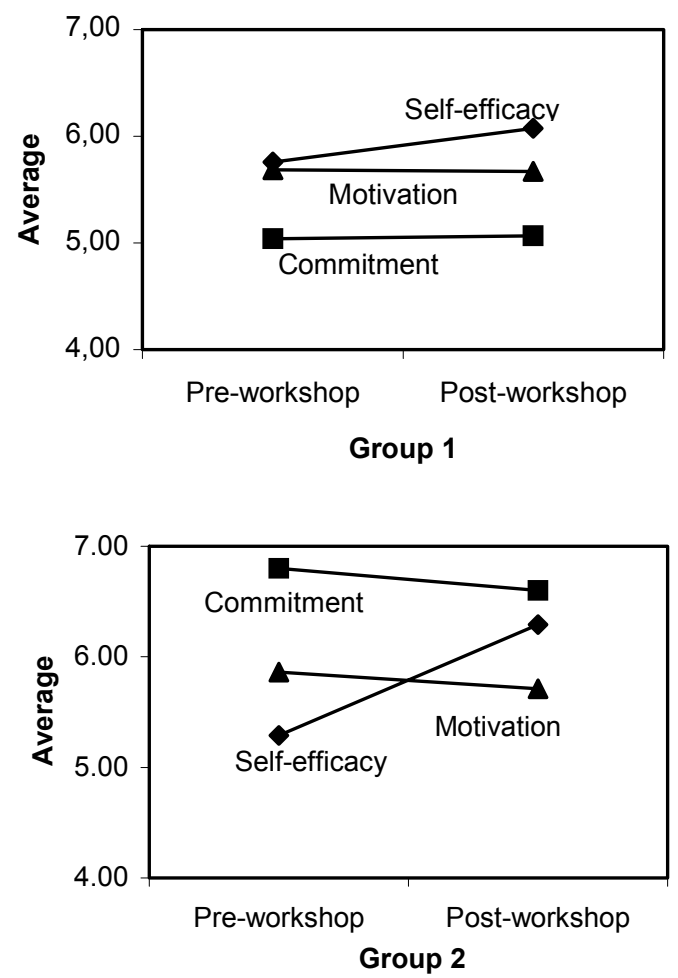

Figure 3. Comparisons of Changes in Attitudes by Learning Styles
However, the increase in self-efficacy was much larger for Group 2 than Group 1 (18.9\% vs. $6.0 \%$ ). The data was further analyzed by learning styles (see Table 2 and Figure 3). Group 2 shows higher attitudes in all three aspects than Group 1.

\subsubsection{Organizational Commitment}

Group 1, which has a high preference for cooperative learning, increased slightly in mean scores of commitment from pre to post-workshop $(0.6 \%)$. In turn, Group 2, which has a high preference for cooperative and competitive learning, had a decrease in mean scores of commitment from pre to post-workshop (-2.9\%). This may imply that for individuals who are more competitive, organizational commitment may somewhat decrease when it requires collaboration.

\subsubsection{Motivation}

Motivation was slightly less positive after completing the workshop for both groups. However, the decrease was greater for Group 2 than Group 1. The mean difference for Group 1 is .02 $(-0.35 \%)$ and the mean difference for Group 2 is $.15(-2.6 \%)$ (see Table $2 \&$ Figure 3 ). This implies that learning about collaboration may slightly decrease one's motivation to collaborate for individuals with a highly competitive learning style preference. 
Table 3. Overall Workshop Evaluation by Learning Preferences

\begin{tabular}{|c|c|c|c|c|c|c|}
\hline \multirow{2}{*}{ Survey Item (scale 1 to 7 ) } & \multicolumn{3}{|c|}{ Group $1^{a}(n=5)$} & \multicolumn{3}{|c|}{ Group $2^{\mathrm{b}}(\mathrm{n}=1)$} \\
\hline & Day 1 & Day 2 & $\%$ change & Day 1 & Day 2 & $\%$ change \\
\hline Contents & 6.20 & 6.80 & +9.7 & 5.40 & 5.40 & 0 \\
\hline Meeting expectation & 5.93 & 6.75 & +13.8 & 4.33 & 4.33 & 0 \\
\hline Facilitator's delivery & 6.40 & 6.75 & +5.5 & 6.33 & 7.00 & +10.6 \\
\hline Personal participation & 5.40 & 6.25 & +15.7 & 7.00 & 7.00 & 0 \\
\hline Willingness to practice skills & 5.73 & 6.13 & +7.0 & 5.33 & 5.50 & +3.2 \\
\hline Average overall response & 5.92 & 6.54 & +10.5 & 5.68 & 5.85 & +3.0 \\
\hline
\end{tabular}

${ }^{a}$ High preference for cooperative learning

${ }^{\mathrm{b}}$ High preference for cooperative and competitive learning

\subsection{Participants' Overall Perceptions}

Group 1 who has a high preference for the cooperative learning style evaluated the workshop more positively overall than Group 2 who has high preference for cooperative and competitive learning styles. As illustrated in Table 3, Group 2 responses were consistently lower than Group 1 responses except for personal participation (both days) and facilitator's delivery (day 2). This may be due to individual ranking differences, or indicate that individuals with a highly competitive learning style do not value training in collaboration as much as others. Further research is required to investigate this finding.

In every aspect, Day 2 was rated higher than Day 1 by Group 1 (Table 3.) Only 2 categories, facilitator's delivery and willingness to practice skills, were rated higher for Day 1 than Day 2 by Group 2. The other three categories, content, meeting expectation and personal expectation, were rated the same for both days by Group 2 . These results may indicate that learning through hands-on activities engages and provides content to a greater extent for students with cooperative learning styles than students who also have a competitive learning style preference. In addition to the quantitative items, the survey included several open-ended questions asking about highlights, low spots and suggestions regarding the workshop. These data mirror the survey responses. Comments from Group 1 participants were more enthusiastic in nature than comments from Group 2. For example, participants in Group1 reported:
This workshop is a wonderful experience and I hope it becomes part of the...requirements for all students and faculty! (Undergraduate student)

[Low spots?] None. I thought today's workshop was great. (Graduate student)

[Low spots?] I didn't find any. (Graduate student)

Regardless of learning styles, the small group exercise and discussion were rated most useful and relevant by all participants. However, reasons why varied somewhat between the groups. Participants in Group 1 reported:

The group exercise was particularly effective in illustrating communication within a group and how it can affect the outcome.

(Graduate student)

[Highlights?] The group exercise - we were able to view different strategies and how well they worked in a particular group.

(Undergraduate student)

Group 2 reported:

Group exercise, group discussions. These parts of the workshop made me think about ways to accomplish the group's goal while achieving my personal goal.

(Graduate student) 
It is interesting to note that in the above quote, the Group 2 participant acknowledges group goals and also the importance of personal goals. We propose this reflects the participant's cooperative and competitive learning styles.

Group 1 participant also enjoyed learning about emerging technologies that support collaboration, whereas this was not highlighted by Group 2. For example, participants in Group 1 commented:

We are "old-fashioned" scientists, who normally share notes and ideas through talking. It's great to learn that in the modern world, there are technologies that can more effectively break the geographic barriers to having people together. (Postdoc)

[I liked] the demonstrations of [collaboration technology research projects]. These look like emerging new innovations that will help facilitate better communication and collaboration among scientists. (Graduate student)

Open-ended comments further indicate that both learning style groups had suggestions for improving the workshop. Recommendations from Group 1 participants focused on:

More discussions and examples

(Graduate student)

More group activities

(Undergraduate student)

More demonstrations/role playing

(Graduate student)

More real scenario analysis (Postdoc)

In comparison, the participant in Group 2 suggested:

Add clear theories which can improve a person's communication and collaboration skills. (Graduate student)

Thus Group 2's suggestion focuses more on the individual, indicating an inclination towards individual improvement. All participants were natural scientists and in natural science, theories are laws that govern behavior. Perhaps individuals with competitive learning styles prefer learning about rules that they can individually apply.

\section{CONCLUSION}

This study investigated how a workshop on collaboration and ICT was perceived by participants with different learning style preferences. Multiple type of learning outcomes were measured using valid and reliable instruments reported in the literature.

After completion of a two-day workshop, Group 2 who had strong preferences for cooperative and competitive learning styles reported a greater increase in self-efficacy than Group 1 on average ( $18.9 \%$ vs. $6.0 \%)$, but with a decrease in organizational commitment $(-2.9 \%$ vs. $+0.6 \%$ ). Group 1 who had a strong preference primarily for the cooperative learning style overall rated the workshop higher both days (5.92 vs. 5.68 and 6.54 vs. 5.85 ), and this was also reflected in their written evaluations of the workshop. While both groups preferred group discussions and exercises, Group 1 preferred them more strongly as evident in their ratings of Day 2 (when group exercise was held), and in their suggestions to include more group discussion and exercises. While Group 2 also appreciated the discussions and exercise, this appreciation appears to be motivated to a greater extent by self-interests in the workplace, as does Group 2's suggestion for improvement.

Although this was a pilot study with a limited number of participants, our findings indicate that we can expect students who have a strong competitive learning style preference to have different expectations regarding a workshop on collaboration; they may look for content and teaching methods that will primarily increase their individual performance (as compared to group performance). However, previous research, e.g., the concept of contested collaboration (Sonnenwald, 1995; Sonnenwald \& Pierce, 2000), shows that a high degree of self-interest and competition between collaborators can negatively impact the collaboration process and outcomes. Thus, a challenge is how to best teach students with a competitive learning style preference within a workshop, or group, setting. One possible solution may be to explicitly address the 
topic of competition and self-interests in the context of collaboration and learning at the beginning of the workshop. In addition, it appears that information about collaboration should be presented in a variety of formats ranging from examples and role playing to theory.

We should also consider that changing peoples' organizational commitment by providing an educational or training program as an intervention is not an easy task. Increasing organizational commitment may require more time or additional methods, i.e., some type of organizational rewards.

Collaboration is becoming more prevalent in today's organizations. Yet, people might have not the needed knowledge and skills to perform their tasks in interdisciplinary and/or geographically dispersed teams. Considering the lack of efforts providing an educational program on collaboration and ICT in universities, the current study contributes to the research by illustrating the importance of cooperative and competitive learning style preferences to learning outcomes. In particular, learning outcome differences with respect to workshop content based on learning style preferences may be helpful in developing more effective workshops on collaboration and other topics. Further, knowledge of learning style preferences may help increase our understanding of cognitive processes in collaboration. One such cognitive process is information processing by collaborators. Because different learning style modes process information differently (James \& Gardner, 1995), it may be expected that learning style preferences influence collaboration, particularly, collaborative information needs and use, including information sharing and creation. Future research plans include improving the workshop based on these results and replicating this study with a larger number of participants.

Acknowledgements: We would like to thank MaijaLeena Huotari and Fred Sonnenwald for their comments on an earlier draft of this paper, Noriko Hara for leading parts of the workshop, and all study participants who have given generously of their time.

\section{REFERENCES}

Aldenderfer, M.S., \& Blashfield, R.K. (1984). Cluster Analysis. Beverly Hills, California: Sage Publications.
Baldwin, T. T., \& Ford, J. K. (1988). Transfer of training: a review and directions for future research. Personnel Psychology, 41, 63-105.

Baldwin, T., \& Magjuka, R. (1997). Training as an organizational episode: Pretraining influences on trainee motivation. In K. Ford (Ed.), Improving Training Effectiveness in Work Organizations (pp. 99-127). Mahwah, New Jersey: Lawrence Erlbaum Associates.

Bandura, A. (1977). Self-efficacy: Toward a unifying theory of behavioral change. Psychological Review, 84, 191-215.

Bandura, A. \& Beyer, J. (1977). Cognitive processes mediating behavioral change. Journal of Personality and Social Psychology, $\underline{35}, 125-139$.

Barling, J. \& Beattie, R. (1983). Self-efficacy beliefs and sales performance. Journal of Organizational Behavior Management, 5 (Spring), 41-51.

Taylor, S.E., Locke E. A., Lee, C., \& Gist, M. E. (1984). Type A behavior and faculty research productivity: What are the mechanisms? Organizational Behavior and Human Decision Processes, 34: 402-418.

Cannon-Bowers, J. A., Tannenbaum, S.I., Salas, E., \& Volpe, C.E. (1995). Defining competencies and establishing team training requirements. In R. A. Guzzo \& E. Salas (Eds.), Team Effectiveness and Decision Making in Organizations. San Francisco: Jossey-Bass Publishers.

Cooley, E. (1994). Training an interdisciplinary team in communication and decisionmaking skills. Small Group Research, 25(1), 5-25.

Gist, M.E. (1986). The effects of self-efficacy training on training task performance. In F. Hoy (Ed.), Academy of Management Best Paper Proceedings (pp.250-254). Ada, Ohio: Academy of Management.

Gist, M. E. (1989). The influence of training method on self-efficacy and idea generation among managers. Personnel Psychology, 42, 789-805.

Gist, M.E., Schwoerer, C., \& Rosen, B. (1989). Effects of alternative training methods on self-efficacy and performance in computer software training. Journal of Applied Psychology, 74, 884-891. 
Hackman, R. J., \& Walton, R. E. (1986). Leading groups in organizations. In P. S. Goodman and Associates (Eds.), Designing effective work groups (pp. 72-119). San Francisco: Jossey-Bass.

Heinssen, R.K., Glass, C.R. \& Knight, L.A. (1987). Assessing computer anxiety: Development and validation of the computer anxiety rating scale. Computers in Human Behavior, 3(1), 49-59.

Henry, J. W. \& Stone, R. W. (1997). The development and validation of computer selfefficacy and outcome expectancy scales in a non-volitional context. Behavior Research Methods, Instruments, \& Computers 29 (4), 519-527.

Hill, T., Smith, N.D., \& Mann, M.F. (1987). Role of efficacy expectations in predicting the decision to use advanced technologies: The case of computers. Journal of Applied Psychology, 72, 542-552.

James, W.B. \& Gardner, D.L. (1995). Learning styles: Implications for distance learning. (ERIC Document Reproduction Service No. EJ 514 356)

Johnson, C. (1993). Influences of Gender and Academic Achievement on Learning Preferences of Middle Grade Students. Paper presented at the Annual Meeting of the Mid South Educational Research Association (November 10-12, 1993).

Johnson, C., \& Engelhard, G. (1992). Gender, academic achievement, and preferences for cooperative, competitive, and individualistic learning among African-American adolescents. Journal of Psychology, 126 (4), 385-392.

Johnson, D. \& Johnson, R. (1998). Cooperative learning and social interdependence theory. In R. Scott (Ed). Theory and Research on Small Groups. New York: Plenum Press.

Klatt, Bruce. (1999). The Ultimate Training Workshop Handbook. New York: McGrawHill.

Kraiger, K., Ford, J. \& Salas, E. (1993). Application of cognitive, skill-based, and affective theories of learning outcomes to new methods of training evaluation. Journal of Applied Psychology, 78, 311-328.
Lawler, E.E. (1981). Pay and Organizational Development. Reading, MA: AddisonWesley.

Leonard, N.H., Beauvais, L.L, \& Scholl, R.W. (1995). A self concept-based model of work motivation. Paper presented at the Annual Meeting of the Academy of Management.

Lurey, Jeremy S. (1998). A Study of Best Practices in Designing and Supporting Effective Virtual Teams. Unpublished doctoral dissertation: California School of Professional Psychology.

Mathieu, J.E., Tannenbaum, S.I. \& Salas, E. (1992). Influences of individual and situational characteristics on measures of training effectiveness. Academy of Management Journal, 35, 828-847.

Mowday, R.T., Porter, L.W., \& Steers, R.M. (1982). Employee-organization linkages: The psychology of commitment, absenteeism, and turnover. San Diego, CA: Academic Press.

Noe, R. A., \& Schmitt, N. (1986). The influence of trainee attitudes on training effectiveness: Test of a model. Personnel Psychology, 39, 497-523.

Noe, R.A. (1986). Trainee attitudes and attributes: Neglected influences of training effectiveness. Academy of Management Review, 11, 736-749.

Owens, L., \& Barnes, J. (1992). Learning Preference Scales: Handbook and test master set. Melbourne: Australian Council for Education Research Ltd.

Owens, L., \& Straton, R. (1980). The development of a co-operative, competitive, and individualized learning preference scale for students. British Journal of Educational Psychology, 50, 147-161.

Raskar, R., Welch, G., Cutts, M., Lake, A., Stesin, L., \& Fuchs, H. (1998). The office of the future: A unified approach to imagebased modeling and spatially immersive displays. ACM Computer Graphics Proceedings.

Rosen, L.D. \& Weil, M.L. (1994). Computer Anxiety: A cross-cultural comparison of university students in ten countries. Computers in Human Behaviors, 8(1), 45-64.

Schunk, D. (1996). Learning Theories: An Educational Perspective. Englewood Cliffs, NJ: Prentice-Hall. 
Simonin, B. L. (1997). The importance of collaborative know-how: An empirical test of the learning organization. Academy of Management Journal, 40(5), 1150-1174.

Smith, R.M. (1982). Learning how to learn: Applied theory for adults. Englewood Cliffs, NJ: Prentice Hall.

Sonnenwald, D. H. (1995). Contested collaboration: a descriptive model of intergroup communication in information system design. Information Processing and Management, 31(6), 859-877.

Sonnenwald, D.H. (1999). Challenges in Corporate and University R\&D Collaboration. INFORMS (Institute for Operations Research and Management Science) Annual Conference, Cincinnati, $\mathrm{OH}$. Sonnenwald, D.H., \& Pierce, K. (2000). Information behavior in dynamic group work contexts: Interwoven situational awareness, dense social networks and contested collaboration. Information Processing \& Management, 36(3), 461-479.
Sonnenwald, D.H., Bergquist, R., Maglaughlin, K.A., Kupstas-Soo, E., \& Whitton, M. (2001). Designing to support collaborative scientific research across distances: The nanoManipulator example. In E. Churchill, D. Snowdon, A. Munro (Eds.), Collaborative Virtual Environments (pp. 202-224). London: Springer Verlag.

Stevens, Michael J., \& Campion, Michael A. (1994). The knowledge, skill, and ability requirement for teamwork: implications for human resource management. Journal of Management, 20(2), 503-530.

Tannenbaum, S.I., Mathieu, J.E., Salas, E., \& Cannon-Bowers, J.A. (1991). Meeting trainees' expectations of commitment, selfefficacy, and motivation. Journal of Applied Psychology, 76(6), 759-769.

Taylor, M.S., Locke, E.A., Lee, C., \& Gist, M.E. (1984). Type A behavior and faculty research productivity: What are the mechanisms? Organizational Behavior and Human Performance, 34, 402-418. 